\title{
Graceful Labeling and Skolem Graceful Labeling on the U-star Graph and It's Application in Cryptography
}

\author{
Meliana Pasaribu' ${ }^{1}$, Yundari2 ${ }^{*}$, Muhammad Ilyas $^{3}$ \\ 1,2,3 Mathematics Department, Faculty of Mathematics and Natural Sciences, Universitas Tanjungpura, \\ Pontianak, Indonesia \\ *Corresponding Author. Email:yundari@math.untan.ac.id
}

\begin{abstract}
Graceful Labeling on graph $\mathrm{G}=(\mathrm{V}, \mathrm{E})$ is an injective function $f$ from the set of vertex $\mathrm{V}(\mathrm{G})$ to the set of numbers $\{0,1,2, \ldots,|E(G)|\}$ which induces bijective function $f$ from the set of edges $\mathrm{E}(\mathrm{G})$ to the set of numbers $\{1,2, \ldots,|\mathrm{E}(\mathrm{G})|\}$ such that for each edge $u v \in \mathrm{E}(\mathrm{G})$ with $\mathrm{u}, \mathrm{v} \in \mathrm{V}(\mathrm{G})$ in effect $f(u v)=|f(u)-f(v)|$. Meanwhile, the Skolem graceful labeling is a modification of the Graceful labeling. The graph has graceful labeling or Skolem graceful labeling is called graceful graph or Skolem graceful labeling graph. The graph used in this study is the U-star graph, which is denoted by $U\left(S_{n}\right)$. The purpose of this research is to determine the pattern of the graceful labeling and skolem graceful labeling on graph $\mathrm{U}\left(\mathrm{S}_{\mathrm{n}}\right)$ apply it to cryptography polyalphabetic cipher. The research begins by forming a graph $U\left(S_{n}\right)$ and they are labeling it with graceful labeling and Skolem graceful labeling. Then, the labeling results are applied to the cryptographic polyalphabetic cipher. In this study, it is found that the $U\left(S_{n}\right)$ graph is a graceful graph and a Skolem graceful graph, and the labeling pattern is obtained. Besides, the labeling results on a graph it $\mathrm{U}\left(\mathrm{S}_{\mathrm{n}}\right)$ can be used to form a table $\mathrm{U}\left(\mathrm{S}_{\mathrm{n}}\right)$ polyalphabetic cipher. The table is used as a key to encrypt messages.
\end{abstract}

Keywords:

Graceful Labeling; Skolem Graceful Labeling; Cryptographic

How to Cite:

M. Pasaribu, Y. Yundari, and M. Ilyas, "Graceful Labeling and Skolem Graceful Labeling on the U-star Graph and It's Application in Cryptography," Jambura J. Math., vol. 3, no. 2, pp. 103114,2021

\section{Introduction}

Research on graceful labeling and skolem graceful labeling has been a lot of. Examines the graceful labeling, Skolem graceful labeling, and rho topi labeling on A-star and $\mathrm{H}$ star graphs are found in [1]. However, this research was not included in the development of cryptography. Further research study emphasizes the use of graceful labeling on symmetric trees for cryptography polyalphabetic [2]. Therefore, in this study, the researcher examines the graceful labeling and Skolem graceful labeling a graph and its application to develop cryptography polyalphabetic.

Cryptography is both a science and an art to maintaining the confidentiality of messages. The confidentiality of the message is obtained by encoding the message into

e-ISSN: 2656-1344 (C) 2021 M. Pasaribu, Y. Yundari, M. Ilyas | Under the license CC BY-NC 4.0

Received: 17 February 2021 | Accepted: 26 March 2021 | Online: 4 May 2020 
certain codes. Cryptography is subject contains two parts one is encryption and another one decryption. Encryption is a process of converting plaintext to ciphertext. Decryption is a process of converting the ciphertext to plaintext [3]. Cryptography is categorized into two, namely classical cryptography and modern cryptography [4]. Classical cryptography consists of several types, one of which is cryptography polyalphabetic. Cryptography polyalphabetic cryptography is constructed based on substitution, in particular, using many variables [2].

Cryptography polyalphabetic can be built from various mathematical concepts, one of which is a graph. One of the interesting topics in graph theory that can be applied to cryptography polyalphabetic is graph labeling. A graph labeling assigns integers to the vertices or edges or both subject to a certain condition [5]. In this study, the types of labeling used for the development of cryptography polyalphabetic are graceful labeling and skolem graceful labeling. Skolem graceful labeling on graph $G=(V, E)$ is modification of graceful labeling, i.e. an injective function $f$ of the set of vertex $V(G)$ to the set of numbers $\{0,1,2, \ldots,|E(G)|\}$ which induces the bijective function $f$ from the set of edges $E(G)$ to the set of numbers $\{1,2, \ldots,|E(G)|\}$ where each edge uv $\in E(G)$ with the vertex $u, v \in V(G)$ applies $f(u v)=|f(u)-f(v)|$.

The graph used in this study is a U-star graph $\left(U\left(S_{n}\right)\right)$ with $n \geq 2$ and $n \in \mathbb{N}$. The choice of U-star graph is based on the background of the A-star graph and H-star graph where for each vertex having a degree of one on graph $A$ and graph $H$ being the centre of the star graph $S_{n}$. Then an idea arises if the path graph $P_{n}$ with $n=4$ is modified to form a graph $U$, where for each vertex having a degree of one on graph $U$ is used as the center of the star graph $S_{n}$. So, construct a new graph, namely the U-star graph, denoted by $U\left(S_{n}\right)$. This study aims to determine the pattern of graceful labeling and skolem graceful labeling graph U-star $\left(U\left(S_{n}\right)\right)$ and a graph $S_{n}, 3$ as well as its application to cryptography polyalphabetic. The research begins by reviewing the literature that supports this research. The next is to form a U-star $\left(U\left(S_{n}\right)\right)$ graph and label the graph with graceful labeling step and Skolem graceful labeling. Then the labeling results were applied to the development of cryptography polyalphabetic.

\section{Preliminaries}

Before discussing graceful labeling and Skolem graceful labeling and its application to cryptography polyalphabetic, it must first be given the definition of graphs, degree, order, size, incident, adjacent to cryptography polyalphabetic, which is then used as the basis for further discussion.

Definition 1. [6] A simple graph $G$ is an ordered pair of sets $V(G)$ and $E(G)$ such that the elements of $E(G)$ are unordered pairs of distinct elements of $V(G)$. The elements of $V(G)$ are called the vertices and the elements of $E(G)$ the edges.

Example 1. Given a graph $G$ with the set of vertices $V(G)=\left\{v_{1}, v_{2}, v_{3}, v_{4}, v_{5}\right\}$ and the set of edges $E(G)=\left\{e_{1}, e_{2}, e_{3}, e_{4}, e_{5}, e_{6}\right\}$ where $e_{1}=v_{1} v_{2}, e_{2}=v_{2} v_{3}, e_{3}=v_{3} v_{4}, e_{4}=$ $v_{4} v_{5}, e_{5}=v_{1} v_{5}, e_{6}=v_{2} v_{5}$ So the graph in Figure 1 follows. 


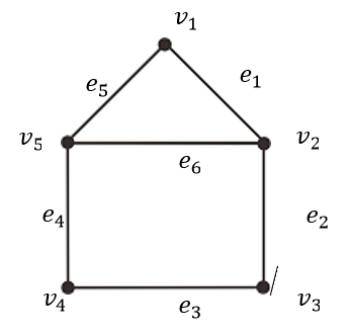

Figure 1. Graph $G$

The next discussion is about a degree, order, size, adjacent, incident, and cryptography polyalphabetic, as outlined in Definition 2, Definition 3, Definition 4, and Definition 5.

Definition 2. [7] The degree of a vertex $v$ in a graph $G$ is the number of edges incident to the vertex $v$.

Definition 3. [8] Given a graph $G$. The number of vertex on graph $G$ is called the order and the number of edges on graph $G$ is called the size. The order of the graph $G$ is denoted by $|V(G)|$ and the size of the graph $G$ is denoted by $|E(G)|$.

Based on Figure 1, it is obtained that $|V(G)|=5$ and $|E(G)|=6$.

Definition 4. [9] Given two vertices $u$ and $v$, if $u, v \in E$ then $u$ and $v$ are said to be adjacent. Furthermore, if an edge $e \in E(G)$ has a vertex $v$ as an endpoint, then $v$ are said incident with e.

Based on Figure 1, it is found that vertex $v_{1}$ and $v_{2}$ are called adjacent, while $e_{1}$ incident with vertex $v_{1}$ and $v_{2}$.

Definition 5. [2] Cryptography polyalphabetic cipher is a cipher constructed based on substitution, specifically using many letter substitution of the alphabet.

The following is given in Figure 2 to show a diagram of the encryption process and message description.

$\stackrel{\text { plaintext }}{\longrightarrow}$ ecryption $\stackrel{\text { ciphertext }}{\longrightarrow}$ decryption $\stackrel{\text { plaintext }}{\longrightarrow}$

Figure 2. Encryption and description process

Given the definition of U-star $\left(U\left(S_{n}\right)\right)$ in Definition 6 below.

Definition 6. A $U$-star graph is a graph obtained from the amalgamation of vertex of a graph $P_{4}$ a shaped $U$-with 2-star graphs $\left(S_{n}\right)$ where each vertex has a degree of one on graph $P_{4}$ is the center of the star graph $\left(S_{n}\right)$.

The U-star graph $\left(U\left(S_{n}\right)\right)$ can be seen in Figure 3 below. 


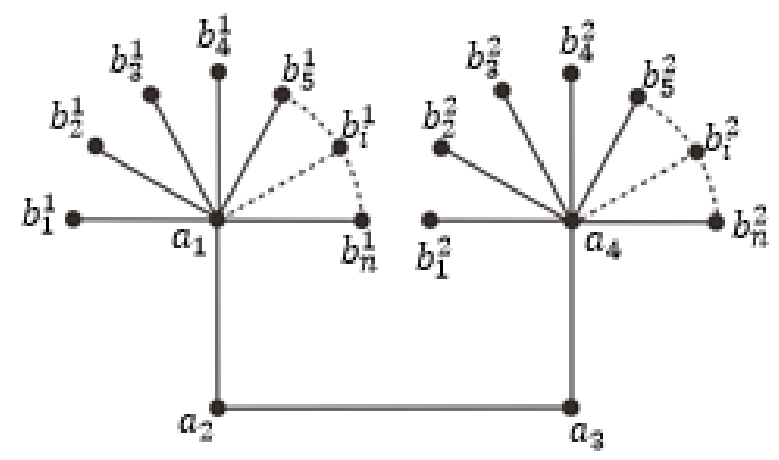

Figure 3. U-Star Graph $\left(U\left(S_{n}\right)\right)$

Based on Figure 3, shows that the graph of U-Star $\left(U\left(S_{n}\right)\right)$ has $2 n+4$ vertices and $2 n+3$ edges.

\section{Result and Discussion}

\subsection{Graceful Labeling and Skolem graceful labeling on U-star Graph}

Before discussing graceful labeling and Skolem graceful labeling graph U-Star $\left(U\left(S_{n}\right)\right)$, it must first be defined graceful labeling and Skolem graceful labeling as follows.

Definition 7. [10] Graceful labeling on graph $G=(V, E)$ is an injective function $f$ of the set of vertexs $V(G)$ to the set of numbers $\{0,1,2, \ldots,|E(G)|\}$ which induces the bijective function $f$ from the set of edges $E(G)$ to the set of numbers $\{1,2, \ldots,|E(G)|\}$ where each edge uv $\in E(G)$ with the vertex $u, v \in V(G)$ applies $f(u v)=|f(u)-f(v)|$.

Definition 8. [11] A graph $G=(V, E)$ is said to be Skolem graceful labeling if there exists an injective function $g$ of the set of vertices $V(G)$ to the set of numbers $\{1,2, \ldots,|V(G)|\}$ such that the induced function $g$ from the set of edges $E(G)$ to the set of numbers $\{1,2, \ldots,|E(G)|\}$, defined by $g(u v)=|g(u)-g(v)|$ is a bijection, where $u v \in E(G)$.

Based on Figure 3, the U-star $\left(U\left(S_{n}\right)\right)$ graph and the $S_{n}$ graphs can be constructed into a graceful graph and a Skolem graceful as outlined in the following theorems.

Theorem 1. The U-star graph $\left(U\left(S_{n}\right)\right)$ is a graph graceful for $n \geq 2, n \in N$.

Proof Given the graph U-Star $\left(U\left(S_{n}\right)\right)$ for $n \geq 2, \mathrm{n} \in \mathbb{N}$. Based on Figure 3, it is known that $V\left(U\left(S_{n}\right)\right)=\left\{a_{1}, a_{2}, a_{3}, a_{4}, b_{1}^{1}, \ldots, b_{i}^{1}, \ldots, b_{n}^{1}, b_{1}^{2}, \ldots, b_{i}^{2}, \ldots, b_{n}^{2}\right\}$ and $E\left(U\left(S_{n}\right)\right)=$ $\left\{a_{m} a_{m+1}, a_{1} b_{1}^{1}, \ldots, a_{1} b_{i}^{1}, \ldots, a_{1} b_{n}^{1}, a_{4} b_{1}^{2}, \ldots, a_{4} b_{i}^{2}, \ldots, a_{4} b_{n}^{2}\right\}$ with $m=1,2$ and 3 . Besides, it is known that the graph U-Star $\left(U\left(S_{n}\right)\right)$ has as many vertex $2 n+4$ and the total $2 n+3$. The pattern of labeling graceful on graph $U\left(S_{n}\right)$ as follows.

$$
\begin{aligned}
f\left(a_{1}\right) & =0 \\
f\left(a_{2}\right) & =2 n+2 \\
f\left(a_{3}\right) & =n \\
f\left(a_{4}\right) & =1 \\
f\left(b_{i}^{1}\right) & = \begin{cases}2 n+3, & \text { if } i=1 \\
2 n+3-i, & \text { if } i>1\end{cases} \\
f\left(b_{i}^{2}\right) & = \begin{cases}n+\left(\frac{2}{i}\right), & \text { if } i \leq 2 \\
n-(i-2), & \text { if } i>2\end{cases}
\end{aligned}
$$


Where $i=1,2, \ldots, n$.

1. We will prove that every $n \geq 2, n \in N$, the function $f$ maps $V\left(U\left(S_{n}\right)\right)$ to $\left\{0,1,2, \ldots,\left|E\left(U\left(S_{n}\right)\right)\right|\right\}$

a. For vertex $a_{1}, a_{2}, a_{3}$ and $a_{4}$

Known that $f\left(a_{1}\right)=0, f\left(a_{2}\right)=2 n+2, f\left(a_{3}\right)=n$ and $f\left(a_{4}\right)=1$ so that for every $n \geq 2$ then $f\left(a_{1}\right), f\left(a_{2}\right), f\left(a_{3}\right)$ and $f\left(a_{4}\right)$ always map to $\{0,1,2, \ldots,|2 n+3|\}$.

b. For vertex $b_{i}^{1}$ dengan $i=1,2, \ldots, n$

Know $f\left(b_{i}^{1}\right)=2 n+3$ to $i=1$ and $f\left(b_{i}^{1}\right)=2 n+3-i$ for $i>1$.

Case 1: $i=1$

Since $n \geq 2$, then obviously $f\left(b_{i}^{1}\right)$ always mapped to $\{0,1,2, \ldots,|2 n+3|\}$

Case 2: $i>1$

Since $i>1$ and $n \geq 2$, then $2 \leq n<2 n+3-i<2 n+3$. Otherwise

$0<2$, consequently $0<2 n+3-i<2 n+3$. So that we get

$0<f\left(b_{i}^{1}\right)<2 n+3$.

c. For $b_{i}^{2}$ with $i=1,2, \ldots, n$

Know $f\left(b_{i}^{2}\right)=n+\left(\frac{2}{i}\right)$ for $i \leq 2$ and $f\left(b_{i}^{2}\right)=n(i-2)$ for $i>2$.

Case 1: $i \leq 2$

Since $i \leq 2$ and $n \geq 2$, then $n \leq n+\left(\frac{2}{i}\right) \leq 2 n$. Besides that $0<n$ and

$2 n<2 n+3$, consequently $0<n+\left(\frac{2}{i}\right)<2 n+3$. So that we get

$0<f\left(b_{i}^{2}\right)<2 n+3$.

Case 2: $i>2$

Since $i>2$ and $n \geq 2$, then $2 \leq n-(i-2)<n$. Besides that $0<2$ and $n<2 n+3$, consequently $0<n-(i-2)<2 n+3$. So that

$0<f\left(b_{i}^{2}\right)<2 n+3$.

Thus, it is proved that the function $f$ maps $V\left(U\left(S_{n}\right)\right)$ to $\left\{0,1,2, \ldots,\left|E\left(U\left(S_{n}\right)\right)\right|\right\}$.

2. We show that $f$ the function is injective

a. To vertex $a_{2}$ and $a_{3}$

Given $f\left(a_{2}\right)=2 n+2$ and $f\left(a_{3}\right)=n$ with $n \geq 2$. Based on the pattern of graceful labeling on vertices $a_{2}$ and $a_{3}$, it can be seen that the labels at vertices $a_{2}$ and $a_{3}$ are injective to $\{0,1,2, \ldots,|2 n+3|$.

b. For vertex $b_{i}^{1}$

Know $f\left(b_{i}^{1}\right)=2 n+3$ to $i=1$ and $f\left(b_{i}^{1}\right)=2 n+3-i$ for $i>1$.

Case 1: $i=1$

Based on the labeling pattern graceful defined at a vertex $b_{1}^{1}$, it can be seen that the label at the vertex $b_{1}^{1}$ is injective to $\{0,1,2, \ldots,|2 n+3|\}$

Case 2: $i>1$

Take any vertex $b_{i}^{1}, b_{k}^{1} \in V\left(U\left(S_{n}\right)\right)$ where $f\left(b_{i}^{1}\right)=f\left(b_{k}^{1}\right)$. Define $f\left(b_{i}^{1}\right)=2 n+3-i$ and $f\left(b_{k}^{1}\right)=2 n+3-k$. Since $f\left(b_{i}^{1}\right)=f\left(b_{k}^{1}\right)$ then $2 n+3-i=2 n+3-k$, consequently $i=k$. Since $=k, b_{i}^{1}=b_{k}^{1}$.

c. For vertex $b_{i}^{2}$ 
Know $f\left(b_{i}^{2}\right)=n+\left(\frac{2}{i}\right)$ for $i \leq 2$ and $f\left(b_{i}^{2}\right)=n(i-2)$ for $i>2$. Take any vertex $b_{i}^{2}, b_{k}^{2} \in V\left(U\left(S_{n}\right)\right)$ where $f\left(b_{i}^{2}\right)=f\left(b_{k}^{2}\right)$.

Case 1: $i \leq 2$

Define $f\left(b_{i}^{2}\right)=n+\left(\frac{2}{i}\right)$ and $f\left(b_{k}^{2}\right)=n+\left(\frac{2}{k}\right)$. Since $f\left(b_{i}^{2}\right)=f\left(b_{k}^{2}\right)$ then $n+\left(\frac{2}{i}\right)=n+\left(\frac{2}{k}\right)$, the result is $i=k$. Since $=k, b_{i}^{2}=b_{k}^{2}$. So it is proven that $f\left(b_{i}^{2}\right)$ is an injective function towards $\{0,1,2, \ldots,|2 n+3|\}$

\section{Case 2: $i>2$}

Define $f\left(b_{i}^{2}\right)=n-(i-2)$ and $f\left(b_{k}^{2}\right)=n-(k-2)$. Since

$f\left(b_{i}^{2}\right)=f\left(b_{k}^{2}\right)$ then $n-(i-2)=n-(k-2)$, the result is $i=k$. Since $i=k, b_{i}^{2}=b_{k}^{2}$. So, it is proven that $f\left(b_{i}^{2}\right)$ is an injective function concerning $\{0,1,2, \ldots,|2 n+3|\}$.

Therefore, it is proven that $f$ injective function.

3. It will be proved that $f\left(a_{m} a_{m+1}\right), f\left(a_{1} b_{i}^{1}\right)$ and $f\left(a_{4} b_{i}^{2}\right)$ are bijective functions.

It is known that the side of the graph $U\left(S_{n}\right)$ is $a_{m} a_{m+1}, a_{1} b_{i}^{1}$ and $a_{4} b_{i}^{2}$ where $m=$ $1,2,3$ and $i=1,2, \ldots, n$. Furthermore, it is known that the set of sides $E\left(U\left(S_{n}\right)\right)$ is mapped to the set of numbers $\left\{1,2, \ldots,\left|E\left(U\left(S_{n}\right)\right)\right|\right\}$, meaning that there are as many as $\left|E\left(U\left(S_{n}\right)\right)\right|$ numbers to label the set of sides $E\left(U\left(S_{n}\right)\right)$. So to prove that $f\left(a_{m} a_{m+1}\right), f\left(a_{1} b_{i}^{1}\right)$ and $f\left(a_{4} b_{i}^{2}\right)$ are bijective functions, it is sufficient to prove that $f\left(a_{m} a_{m+1}\right), f\left(a_{1} b_{i}^{1}\right)$ and $f\left(a_{4} b_{i}^{2}\right)$ is always different for $m=1,2$ and 3 and $i=1,2, \ldots, n$.

a. For $a_{m} a_{m+1}$ where $m=1,2$ and 3

The labeling function on edge defined as $a_{m} a_{m+1}$ is $f\left(a_{m} a_{m+1}\right)=\mid f\left(a_{m}\right)-$ $f\left(a_{m+1}\right) \mid$. It will be proven that $f\left(a_{m} a_{m+1}\right)$ is always different for every $m=$ $1,2,3$.

Case 1: $m=1$

$$
\begin{aligned}
f\left(a_{1} a_{2}\right) & =\left|f\left(a_{1}\right)-f\left(a_{2}\right)\right| \\
& =|0-(2 n+2)| \\
& =2 n+2
\end{aligned}
$$

Case 2: $m=2$

$$
\begin{aligned}
f\left(a_{2} a_{3}\right) & =\left|f\left(a_{2}\right)-f\left(a_{3}\right)\right| \\
& =|(2 n+2)-(n)| \\
& =n+2
\end{aligned}
$$

Case 3: $m=3$

$$
\begin{aligned}
f\left(a_{3} a_{4}\right) \quad & =\left|f\left(a_{3}\right)-f\left(a_{4}\right)\right| \\
& =|(n)-1| \\
& =n-1
\end{aligned}
$$

Thus, it is proven that $f\left(a_{m} a_{m+1}\right)$ is always different for every $m=1,2,3$.

4. For $a_{1} b_{i}^{1}$ where $i=1,2, \ldots, n$

Define the labeling function on the side $a_{1} b_{i}^{1}$ is $f\left(a_{1} b_{i}^{1}\right)=\left|f\left(a_{1}\right)-f\left(b_{i}^{1}\right)\right|$. It will be proved that $f\left(a_{1} b_{i}^{1}\right)$ always different for every $i=1,2, \ldots, n$. 
Case 1: $i=1$

$$
\begin{aligned}
f\left(a_{1} b_{1}^{1}\right) & =\left|f\left(a_{1}\right)-f\left(b_{1}^{1}\right)\right| \\
& =|0-(2 n+3)| \\
& =2 n+3
\end{aligned}
$$

Case 2: $i>1$

Taken any edge $a_{1} b_{i}^{1}, a_{1} b_{k}^{1} \in E\left(U\left(S_{n}\right)\right)$ with $a_{1}, b_{i}^{1}, b_{k}^{1} \in V\left(U\left(S_{n}\right)\right)$. It is defined that $f\left(a_{1} b_{i}^{1}\right)=\left|f\left(a_{1}\right)-f\left(b_{i}^{1}\right)\right|$ and $f\left(a_{1} b_{i}^{1}\right)=\left|f\left(a_{1}\right)-f\left(b_{k}^{1}\right)\right|$. It will be proved if $i \neq k$ then $f\left(a_{1} b_{i}^{1}\right)$ always different from $f\left(a_{1} b_{k}^{1}\right)$.

$$
\begin{aligned}
f\left(a_{1} b_{i}^{1}\right) & =\left|f\left(a_{1}\right)-f\left(b_{i}^{1}\right)\right| & f\left(a_{1} b_{k}^{1}\right) & =\left|f\left(a_{1}\right)-f\left(b_{k}^{1}\right)\right| \\
& =|0-(2 n+3-i)| & & =|0-(2 n+3-k)| \\
& =2 n+3-i & & =2 n+3-k
\end{aligned}
$$

Since $i \neq k$ then $2 n+3-i \neq 2 n+3-k$. So, it is proven that $f\left(a_{1} b_{i}^{1}\right) \neq f\left(a_{1} b_{k}^{1}\right)$ for $i>1$.

Thus, it is evident that $f\left(a_{1} b_{i}^{1}\right)$ always different, for $i=1,2, \ldots, n$.

5. For $a_{4} b_{i}^{2}$ where $i=1,2, \ldots, n$

Take any edge $a_{4} b_{i}^{2}, a_{4} b_{k}^{2} \in E\left(U\left(S_{n}\right)\right)$ with $a_{4}, b_{i}^{2}, b_{k}^{2} \in V\left(U\left(S_{n}\right)\right)$. It is defined that $f\left(a_{4} b_{i}^{2}\right)=\left|f\left(a_{4}\right)-f\left(b_{i}^{2}\right)\right|$ and $f\left(a_{4} b_{k}^{2}\right)=\left|f\left(a_{4}\right)-f\left(b_{k}^{2}\right)\right|$. It will be proved if $i \neq k$ then $f\left(a_{4} b_{i}^{2}\right)$ is different from $f\left(a_{4} b_{k}^{2}\right)$.

Case 1: $i \leq 2$

$$
\begin{aligned}
f\left(a_{4} b_{i}^{2}\right) & =\left|f\left(a_{4}\right)-f\left(b_{i}^{2}\right)\right| & f\left(a_{4} b_{k}^{2}\right) & =\left|f\left(a_{4}\right)-f\left(b_{k}^{2}\right)\right| \\
& =\mid 1-\left(n+\left(\frac{2}{i}\right) \mid\right. & & \mid 1-\left(n+\left(\frac{2}{k}\right) \mid\right. \\
& =n+\left(\frac{2}{i}\right)-1 & & n+\left(\frac{2}{k}\right)-1
\end{aligned}
$$

Because $i \neq k$ then $n+\left(\frac{2}{i}\right)-1 \neq n+\left(\frac{2}{k}\right)-1$. So it is proved that $f\left(a_{4} b_{i}^{2}\right) \neq f\left(a_{4} b_{k}^{2}\right)$ for $i \leq 2$.

Case 2: $i>2$

$$
\begin{aligned}
f\left(a_{4} b_{i}^{2}\right) & =\left|f\left(a_{4}\right)-f\left(b_{i}^{2}\right)\right| & f\left(a_{4} b_{k}^{2}\right) & =\left|f\left(a_{4}\right)-f\left(b_{k}^{2}\right)\right| \\
& : \mid 1-(n-(i-2) \mid & & =\mid 1-(n-(k-2) \mid \\
& : n-i+1 & & =n-k+1
\end{aligned}
$$

Because $i \neq k$ then $n-i+1 \neq n-k+1$. So, it is proven that $f\left(a_{4} b_{i}^{2}\right) \neq$ $f\left(a_{4} b_{k}^{2}\right)$ for $i>2$.

therefore, it is proven that $f\left(a_{4} b_{i}^{2}\right)$ always different, for $i=1,2, \ldots, n$.

Based on $\mathrm{a}, \mathrm{b}$, and $\mathrm{c}$, it is evident that $f\left(a_{m} a_{m+1}\right), f\left(a_{1} b_{i}^{1}\right)$ and $f\left(a_{4} b_{i}^{2}\right)$ are always different. Thus, based on 1,2 , and 3 , it is proven that the U-star $\left(U\left(S_{n}\right)\right)$ the graph is a graph graceful for $n \geq 2$ and $n \in N$.

Theorem 2. [12] A tree is skolem graceful if and only if it is graceful.

Proof Let $f$ be graceful labeling of a tree $G$, then $f+1$, defined by $(f+1)(x)=f(x)+1$, for $x \in V(G)$, is a Skolem graceful labeling of G. Conversely, if $f^{\prime}$ is a skolem graceful labeling of $G$, then $f^{\prime}-1$ is graceful labelling of $G$.

Theorem 3. The U-star graph $\left(U\left(S_{n}\right)\right)$ is a graph skolem graceful for $n \geq 2, n \in N$.

Proof Given the graph U-Star $\left(U\left(S_{n}\right)\right)$ with $n \geq 2, \mathrm{n} \in \mathbb{N}$. By using Theorem 2., it is proved that the U-star graph $\left(U\left(S_{n}\right)\right)$ is a Skolem graph graceful for $n \geq 2$ and $n \in N$. 


\subsection{Application of Graceful labeling and Skolem graceful labeling on U-Star Graph in Cryptography}

Application graceful labeling on graph U-Star $\left(U\left(S_{n}\right)\right)$ for cryptographic polyalphabetic utilize their tables $U\left(S_{n}\right)$ polyalphabetic cipher. Table $U\left(S_{n}\right)$ A polyalphabetic cipher is a table constructed from a combination of letters with several punctuation marks. The punctuation marks used in this table are dot (.) and dashes (-). The dash (-) is used to represent a space. The table is used as a key in encrypting a message. The graph used to form the table $U\left(S_{n}\right)$ polyalphabetic cipher is a graph U-Star $\left(U\left(S_{n}\right)\right)$ with $n=12$. The graph was $U\left(S_{12}\right)$ chosen because the number of a vertex on the graph is the $U\left(S_{12}\right)$ same as the number of letters in the alphabet plus dot (.) and dashes (-). Formation of table $U\left(S_{n}\right)$ polyalphabetic cipher starts by forming the graph $U\left(S_{n}\right)$, such that the degree of each vertex at the center of the star graph $S_{n}$ is $n+1$. In this case, the graph used is $U\left(S_{12}\right)$. The shape of the graph $U\left(S_{12}\right)$ can be seen in Figure 4 below.

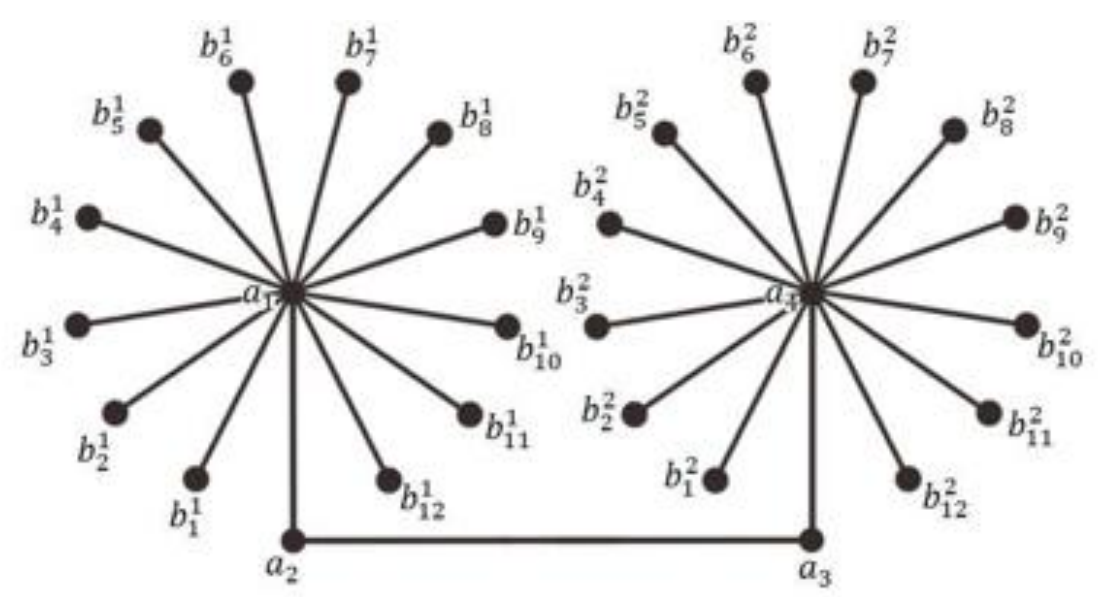

Figure 4. Graph $U\left(S_{12}\right)$

Next, graph $U\left(S_{12}\right)$ is labeled with graceful labeling using the labeling function pattern obtained in Theorem 1. The results of graceful labeling on the graph $U\left(S_{12}\right)$ can be seen in Figure 5 below.

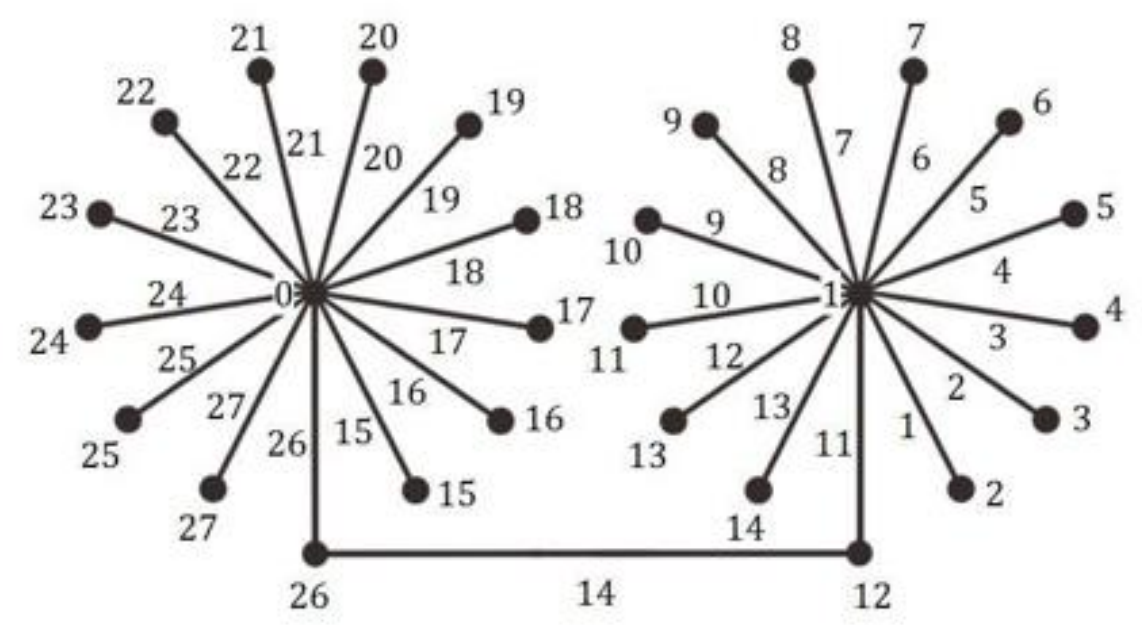

Figure 5. Graceful labeling on graph $U\left(S_{12}\right)$ 
After that, the number of labels on the vertices and edges of the graph is $U\left(S_{12}\right)$ they are transformed into letter labels and punctuation marks. The transformation of the label at the vertex of the graph $U\left(S_{12}\right)$ starts from the numbers $0=a, 1=b, \ldots, 25=z$. Label 26 is transformed into a dot punctuation mark (.), and label 27 is transformed into a dash $(-)$. Meanwhile, the label transformation on the side of the graph $U\left(S_{12}\right)$ starts from the numbers $1=a, 2=b, \ldots, 26=z$, and label 27 is transformed into a dot punctuation mark (.). The results of the label transformation are obtained in Figure 6.

Labels on each side that are directly related to a vertex are written into the table $U\left(S_{n}\right)$ Polyalphabetic cipher. Every column and row are the same in the table $U\left(S_{n}\right)$ The polyalphabetic cipher must have different letters or punctuation marks. It is intended that the ciphertext obtained is more random and avoids the possibility of multiple meanings in the message description process. The still empty blocks are filled with letters or punctuation marks that have not been used in other blocks. The results are obtained in Table 1.

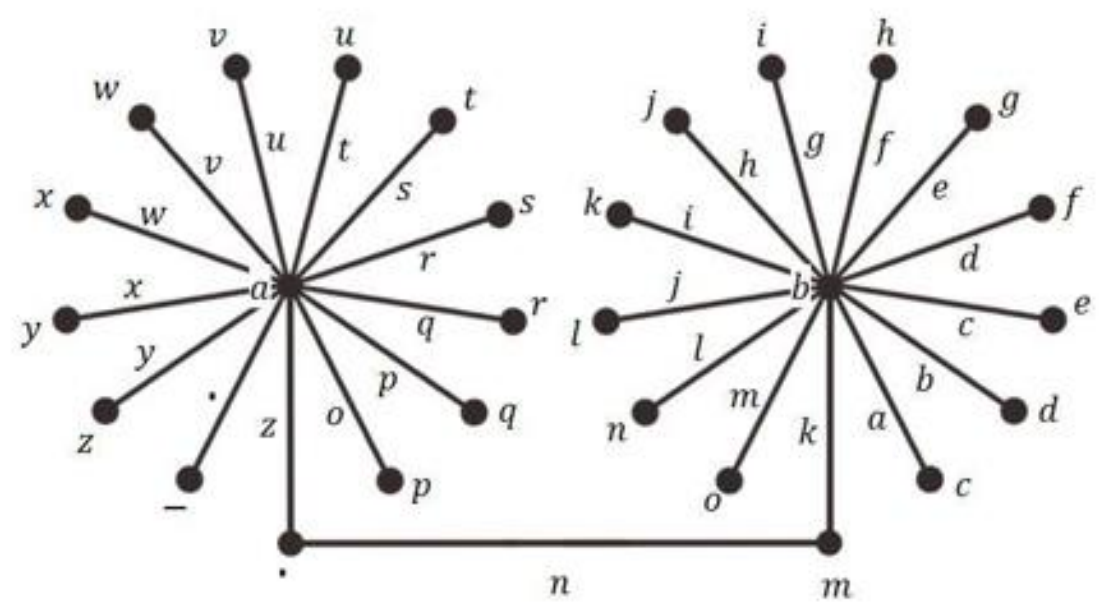

Figure 6. Transformation of labels on graph $U\left(S_{12}\right)$

Furthermore, Table 1 will be used as a key in encryption and message description. Encryption algorithm with $U\left(S_{n}\right)$ polyalphabetic cipher can be seen in Figure 7.

Table 1. $U\left(S_{n}\right)$ polyalphabetic cipher

\begin{tabular}{cllllllllllllll}
\hline Plaintext & \multicolumn{11}{c}{} \\
\hline a & z & o & p & q & r & s & t & U & v & w & x & y & . \\
b & k & a & b & c & d & e & f & G & h & i & j & l & m \\
c & a & z & o & p & q & r & s & T & u & v & w & x & y \\
d & b &. & z & o & p & q & r & S & t & u & v & w & x \\
e & c & y &. & z & o & p & q & R & s & t & u & v & w \\
f & d & x & y &. & z & o & p & Q & r & s & t & u & v \\
g & e & w & x & y &. & z & o & P & q & r & s & t & u \\
h & f & v & w & x & y &. & z & O & p & q & r & s & t
\end{tabular}




\begin{tabular}{|c|c|c|c|c|c|c|c|c|c|c|c|c|c|}
\hline Plaintext & & & & & & & her & ext & & & & & \\
\hline $\mathrm{i}$ & $\mathrm{g}$ & $\mathrm{u}$ & $\mathrm{v}$ & $\mathrm{w}$ & $x$ & $\mathrm{y}$ & . & $Z$ & $\mathrm{O}$ & $\mathrm{p}$ & $\mathrm{q}$ & $\mathrm{r}$ & $\mathrm{s}$ \\
\hline $\mathrm{j}$ & $\mathrm{h}$ & $\mathrm{t}$ & $\mathrm{u}$ & $\mathrm{v}$ & $w$ & $x$ & $\mathrm{y}$ & . & $\mathrm{z}$ & o & $\mathrm{p}$ & - & $\mathrm{n}$ \\
\hline $\mathrm{k}$ & $\mathrm{i}$ & $\mathrm{s}$ & $\mathrm{t}$ & $\mathrm{u}$ & $\mathrm{v}$ & $\mathrm{w}$ & $x$ & $\mathrm{Y}$ & - & - & $\mathrm{n}$ & $\mathrm{p}$ & $q$ \\
\hline 1 & $\mathrm{~J}$ & $\mathrm{r}$ & $\mathrm{s}$ & $\mathrm{t}$ & $\mathrm{u}$ & $\mathrm{v}$ & $\mathrm{w}$ & - & $\mathrm{n}$ & . & $\mathrm{z}$ & o & $\mathrm{p}$ \\
\hline $\mathrm{m}$ & $\mathrm{n}$ & $q$ & $r$ & $\mathrm{~s}$ & $\mathrm{t}$ & - & $\mathrm{n}$ & W & $x$ & $\mathrm{y}$ & . & $\mathrm{z}$ & o \\
\hline $\mathrm{n}$ & 1 & $\mathrm{p}$ & $\mathrm{q}$ & - & $\mathrm{n}$ & $\mathrm{t}$ & $\mathrm{u}$ & $\mathrm{V}$ & $\mathrm{w}$ & $x$ & $\mathrm{y}$ & . & $\mathrm{z}$ \\
\hline o & $\mathrm{m}$ & - & $\mathrm{n}$ & $r$ & $\mathrm{~s}$ & $\mathrm{u}$ & $\mathrm{v}$ & $x$ & $\mathrm{y}$ & $\mathrm{z}$ & o & $\mathrm{q}$ & $\mathrm{r}$ \\
\hline $\mathrm{p}$ & o & $\mathrm{k}$ & $\mathrm{a}$ & $\mathrm{b}$ & $c$ & $\mathrm{~d}$ & e & $\mathrm{F}$ & $\mathrm{g}$ & $\mathrm{h}$ & $\mathrm{i}$ & $\mathrm{j}$ & 1 \\
\hline$q$ & $\mathrm{p}$ & $\mathrm{m}$ & $\mathrm{k}$ & $\mathrm{a}$ & $\mathrm{b}$ & $c$ & $\mathrm{~d}$ & $\mathrm{E}$ & $\mathrm{f}$ & $\mathrm{g}$ & $\mathrm{h}$ & $\mathrm{i}$ & $\mathrm{j}$ \\
\hline $\mathrm{r}$ & $\mathrm{q}$ & 1 & $\mathrm{~m}$ & $\mathrm{k}$ & $\mathrm{a}$ & $\mathrm{b}$ & $\mathrm{C}$ & $\mathrm{D}$ & $\mathrm{e}$ & $\mathrm{f}$ & $\mathrm{g}$ & $\mathrm{h}$ & $\mathrm{i}$ \\
\hline $\mathrm{s}$ & $\mathrm{r}$ & j & 1 & $\mathrm{~m}$ & $\mathrm{k}$ & $\mathrm{a}$ & $\mathrm{b}$ & $\mathrm{C}$ & $\mathrm{d}$ & $\mathrm{e}$ & $\mathrm{f}$ & $\mathrm{g}$ & $\mathrm{h}$ \\
\hline $\mathrm{t}$ & $\mathrm{s}$ & $\mathrm{i}$ & $\mathrm{j}$ & 1 & $\mathrm{~m}$ & $\mathrm{k}$ & $\mathrm{a}$ & B & c & $\mathrm{d}$ & $\mathrm{e}$ & $\mathrm{f}$ & $\mathrm{g}$ \\
\hline $\mathrm{u}$ & $\mathrm{t}$ & $\mathrm{h}$ & $\mathrm{i}$ & $\mathrm{j}$ & 1 & $\mathrm{~m}$ & $\mathrm{k}$ & A & $\mathrm{b}$ & c & $\mathrm{d}$ & $\mathrm{e}$ & $\mathrm{f}$ \\
\hline $\mathrm{v}$ & $\mathrm{u}$ & $\mathrm{g}$ & $\mathrm{h}$ & $\mathrm{i}$ & $\mathrm{j}$ & 1 & $\mathrm{~m}$ & $\mathrm{~K}$ & $\mathrm{a}$ & $\mathrm{b}$ & $c$ & $\mathrm{~d}$ & $\mathrm{e}$ \\
\hline $\mathrm{w}$ & $\mathrm{v}$ & $\mathrm{f}$ & $\mathrm{g}$ & $\mathrm{h}$ & $\mathrm{i}$ & $\mathrm{j}$ & 1 & $\mathrm{M}$ & $\mathrm{k}$ & $\mathrm{a}$ & $\mathrm{b}$ & $\mathrm{n}$ & - \\
\hline$x$ & $\mathrm{w}$ & $\mathrm{e}$ & $\mathrm{f}$ & $\mathrm{g}$ & $\mathrm{h}$ & $\mathrm{i}$ & $\mathrm{j}$ & $\mathrm{L}$ & $\mathrm{m}$ & $\mathrm{n}$ & - & $\mathrm{b}$ & c \\
\hline $\mathrm{y}$ & $x$ & $\mathrm{~d}$ & $\mathrm{e}$ & $\mathrm{f}$ & $\mathrm{g}$ & $\mathrm{h}$ & $\mathrm{i}$ & $\mathrm{N}$ & - & $\mathrm{m}$ & $\mathrm{k}$ & $\mathrm{a}$ & $b$ \\
\hline $\mathrm{z}$ & $\mathrm{y}$ & c & $\mathrm{d}$ & $\mathrm{e}$ & $\mathrm{f}$ & $\mathrm{n}$ & - & I & $\mathrm{j}$ & 1 & $\mathrm{~m}$ & $\mathrm{k}$ & $\mathrm{a}$ \\
\hline . & - & $\mathrm{b}$ & c & $\mathrm{n}$ & - & $\mathrm{f}$ & $\mathrm{g}$ & $\mathrm{H}$ & $\mathrm{i}$ & $\mathrm{j}$ & 1 & $\mathrm{~m}$ & $\mathrm{k}$ \\
\hline- & . & $\mathrm{n}$ & - & $\mathrm{d}$ & $\mathrm{e}$ & $\mathrm{g}$ & $\mathrm{h}$ & $\mathrm{J}$ & 1 & $\mathrm{k}$ & $\mathrm{a}$ & $\mathrm{c}$ & $\mathrm{d}$ \\
\hline
\end{tabular}

\section{Algorithm with U(Sn) polyalphabetic cipher}

Steps of the encryption process as

1. Start

2. Show plaintext

3. Divide plaintext into $n+1$ equal block

4. Show the U(Sn) table of a polyalphabetic cipher

5. Match each letter in the plaintext with the $U(S n)$ table of a polyalphabetic cipher

6. Change each letter in plaintext into ciphertext according to the block sequence in the table $U(S n)$ polyalphabetic cipher

7. Show ciphertext

8. Finish

Given Example 2 below.

Example 2. Given plaintext: Department of Mathematics, Untan

Obtained plaintext and ciphertext, the corresponding areas follows.

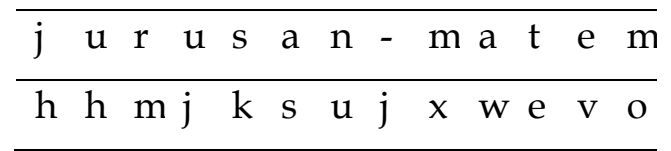

\begin{tabular}{lllllllllll}
\hline $\mathrm{a}$ & $\mathrm{t}$ & $\mathrm{i}$ & $\mathrm{k}$ & $\mathrm{a}$ & - & $\mathrm{u}$ & $\mathrm{n}$ & $\mathrm{t}$ & $\mathrm{a}$ & $\mathrm{n}$ \\
\hline $\mathrm{z}$ & $\mathrm{i}$ & $\mathrm{v}$ & $\mathrm{u}$ & $\mathrm{r}$ & $\mathrm{g}$ & $\mathrm{k}$ & $\mathrm{v}$ & $\mathrm{c}$ & $\mathrm{w}$ & $\mathrm{y}$ \\
\hline
\end{tabular}


Application of labeling the Skolem graceful labeling on a graph $U\left(S_{n}\right)$ for cryptography, polyalphabetic can be performed using the same steps as apply graceful labeling to a graph $U\left(S_{n}\right)$ for cryptography polyalphabetic. The graph used is a U-star graph $\left(U\left(S_{n}\right)\right)$ with $n=12$. The Skolem graceful labeling on the graph $U\left(S_{12}\right)$ can be done using Theorem 3.2. The transformation of number labels into letter labels on vertex and edges of the graph $U\left(S_{n}\right)$ starts from the numbers $1=a, 2=b, \ldots, 26=z$. Meanwhile, number 27 is transformed into a dot punctuation mark (.), and number 28 is transformed into a dash (-).

\section{Conclusion}

Based on the above discussion, it can be concluded that a U-star $\left(U\left(S_{n}\right)\right)$ graph is a graceful graph and a Skolem graceful. Besides, the graceful labeling and Skolem graceful labeling graph U-Star $\left(U\left(S_{n}\right)\right)$ can be used to generate a table of $U\left(S_{n}\right)$ polyalphabetic cipher. The table is then used as a key for encryption and description of the message or information.

\section{References}

[1] N. Huda and Z. Amri, "Pelabelan Graceful, Skolem Graceful dan Pelabelan Rho Topi Pada Graf A-Bintang dan H-Bintang," Jurnal Matematika Murni dan Terapan EPSILON, vol. 6, no. 2, pp. 30-37, 2012.

[2] I. B. Mukyas and K. A. Sugeng, "Uses of Graceful Labeling on Symmetric Trees for Polyalphabetic Cryptography," Proceedings of the National Mathematics Conference XVII, pp. 1417-1420, 2014.

[3] S. A. Hanna and A. M. Asif, "Analysis of Polyalphabetic Transposition Cipher Techniques used for Encryption and Decryption," International Journal of Computer Science and Software Engineering (IJCSSE), vol. 6, pp. 41-46, 2017.

[4] J. Juliandi, B. Prihandono and N. Kusumastuti, "Classical Cryptography Using Modified Affine Cipher Methods Reinforced with Vigenere Cipher," Buletin Ilmiah Matematika, Statistika, dam Terapannya, vol. 2, pp. 87-92, 2013.

[5] S. K. Vaidya and C. M. Barasara, "Edge Product Cordial Labeling of Graph," Journal Mathematics, Computation and Science, vol. 2, pp. 1436-1450, 2012.

[6] S. C. Lopez and F. A. Muntaner-Batle, Graceful, Harmonious, and Magic Type Labellings Relations and Techniques, Switzerland: Springer, 2017.

[7] G. Chartrand, L. Lesniak and P. Zhang, Graphs and Digraphs Fifth Edition, New York: Taylor and Francis Group, 2011.

[8] G. Chartrand and O. R. Oellermann, Applied and Algorithmic Graph Theory, New York: McGraw-Hill, 1993.

[9] J. M. Harris, J. L. Hirst and M. J. Mossinghoff, Combinatorics and Graph Theory Second Edition, New York: Springer, 2008.

[10] A. Z, T. H. Harahap and Irvan, "Graceful Labelling and rho Labeling on The 8Bintang Graph," Buletin of Mathematics, vol. 10, no. 2, pp. 111-119, 2018. 
[11] S. M. Lee and S. C. Shee, "On Skolem Graceful Graph," Discrete Mathematics, vol. 93, pp. 195-200, 1991.

[12] E. Mendelshon and N. Shalaby, "On Skolem labelling of windmills," Ars Combin. Des, vol. 7, no. 3, pp. 185-203, 1999.

This article is an open-access article distributed under the terms and conditions of the Creative Commons Attribution-NonCommercial 4.0 International License. Editorial of JJoM: Department of Mathematics, Universitas Negeri Gorontalo, Jln. Prof. Dr. Ing. B.J. Habibie, Moutong, Tilongkabila, Kabupaten Bone Bolango, Provinsi Gorontalo 96119, Indonesia. 